\title{
O ENSINO COM PESQUISA: REALIDADE, DESAFIOS E PERSPECTIVAS NA UNIVERSIDADE BRASILEIRA
}

\author{
TEACHING WITH RESEARCH: REALITY, CHALLENGES \\ AND PERSPECTIVES IN THE BRAZILIAN UNIVERSITY \\ L'ENSEIGNEMENT AVEC LA RECHERCHE : RÉALITÉ, DÉFIS \\ ET PERSPECTIVES DANS L'UNIVERSITÉ BRÉSILIENNE \\ LA ENSEÑANZA CON INVESTIGACIÓN: REALIDAD, DESAFÍOS \\ Y PERSPECTIVAS EN LA UNIVERSIDAD BRASILEÑA
}

Ernâni Lampert *

\section{RESUMO}

O ensino com pesquisa, abordado neste artigo, é uma proposta metodológica inovadora e que tem repercussão na qualidade do ensino. Numa primeira instância, o autor localizará e contextualizará a problemática. Durante o discurso, deixará claro que a pesquisa é a principal função da universidade e analisará a sua importância. Fará uma série de indagaçôes sobre esta problemática, pois uma das características dos investigadores contemporâneos é o questionamento. Na segunda parte, analisará a pesquisa com ensino como uma das possibilidades metodológicas que o professor da educação superior poderá utilizar. Destacará o significado, a importância, o respaldo teórico, as mudanças que esta metodologia provoca no papel do professor e do aluno. Como culminância, tecerá algumas ponderações para reflexão sobre a realidade, os desafios e perspectivas do ensino com pesquisa na universidade brasileira. Palavras-chave: Ensino com pesquisa. Educação superior. Metodologia do ensino. Pesquisa.

* Doutor (1995) e Pós-Doutor (2001) em Educação pela Universidad Pontifícia de Salamanca, Espanha. Professor Associado da Fundação Universidade Federal do Rio Grande - RS (erncas@bol.com.br). 


\section{CONTEXTUALIZAÇÃO DA PROBLEMÁTICA}

Na universidade brasileira, quer nos cursos de graduação, quer nos programas de pósgraduação, a pesquisa é praticamente relegada. Há uma preocupação muito acentuada com o formalismo do ensino (normalmente a reprodução de conhecimentos) em detrimento da produção do saber. Os currículos dos cursos, na maioria das vezes, são constituídos de listagem de disciplinas, com conteúdos descontextualizados da realidade e entre si, e que não necessariamente propiciam a realização da investigação. Os professores, com algumas exceções, não estão preparados, não possuem as condições apropriadas e nem estão predispostos a trabalhar o ensino com e para a pesquisa, pois nem sempre o currículo permite e geralmente há uma sobrecarga de trabalho. Dados do Instituto Nacional de Estudos e Estatísticas Educacionais Anísio Teixeira (Inep) (2006) mostram que, em 2005, 74,6\% dos docentes com tempo integral estavam nas instituições públicas e somente $16,3 \%$ nas instituições particulares. Além deste fato, não se pode esquecer que há a categoria de professor horista, aquele que somente ministra aulas. Em relação à titulação, 40,1\% dos doutores exerciam suas atividades em instituições públicas e 12,3\% nos estabelecimentos privados.

Os discentes, por sua vez, acostumados com o ensino conservador e fragmentado, na maioria das vezes, demonstram certa resistência a algum câmbio na metodologia de ensino. As disciplinas direcionadas à pesquisa (Metodologia Científica e/ou Métodos e Técnicas de Pesquisa), questionáveis por muitos, pois os conteúdos deveriam ser trabalhados pelo conjunto dos docentes, geralmente tratam aspectos da lógica e normas da ABNT (Associação Brasileira de Normas Técnicas), em vez de mostrar ao discente a necessidade e a importância da investigação para a vida do cidadão, da universidade e da sociedade. Observa-se, pela organização curricular, pelo despreparo proposital de docentes, pela sobrecarga do professor, pelo desprovimento de recursos, que há pouco interesse em se difundir a pesquisa, a não ser quando convém a determinados grupos e/ou para a manutenção do status quo.

É de conhecimento público que a pesquisa pode ser perigosa desvendando, elucidando fatos/fenômenos e desmistificando verdades até então aceitas como universais. Ela é de mostrar a realidade sob diferentes olhares: como as pessoas vivem, sobrevivem; são excluídas e colocadas à margem de uma sociedade cada vez mais competitiva, cujo único valor aceito é o lucro. Através da pesquisa, a pessoa é capaz de perceber claramente as gritantes injustiças e diferenças sociais existentes na sociedade brasileira e no mundo capitalista. A pesquisa é uma porta que se abre para desvendar o mundo. Será oportuno para o "capital" mostrar à população o mundo como ele realmente é ou é melhor apresentar somente alguns recortes?

Denota-se que, mesmo sem muitas condições de infra-estrutura, entre os pesquisadores que aqui se destacam muitos emigram para outros países (Estados Unidos, Canadá, “Tigres Asiáticos" e Europa) onde a investigação científica em praticamente todas as 
áreas do conhecimento humano e o trabalho do pesquisador têm o seu reconhecimento. Infelizmente, no Brasil, salvo particularizações, nem ensino nem pesquisa são contemplados. Sabe-se que tudo isso não acontece por acaso. É necessário atribuir essa causalidade ao contexto político e econômico, atrelado ao interesse do capital, e, na medida do possível, reverter o quadro. Ao contrário, em pouco tempo a função básica de pesquisa desaparecerá da universidade. Certamente alguns pesquisadores serão absorvidos pelo próprio sistema e outros tantos ficarão à margem, como vem ocorrendo atualmente com a demissão de doutores no ensino superior privado.

A idéia de pesquisa na universidade não é recente, e diferentes autores nacionais e internacionais, ao longo do tempo, enfatizam o ensino e a pesquisa como funções essenciais da universidade. Para Herrera Gonzáles (1986), a universidade não somente prepara para a vida profissional, mas também tem como missão a investigação, a busca de novas técnicas, novos produtos e novas aplicações. Conforme Botey (1988), desde suas origens, a função da universidade é dupla: investigação e docência. De acordo com Hoffmann (1985), a universidade deve ser organizada e estruturada para a vida moderna a fim de atender às principais funçóes: a pesquisa (buscando e organizando os conhecimentos) e o ensino (distribuindo conhecimentos). No parecer de Tójar Hurtado (1997), a universidade, para desenvolver suas funções, precisa de pesquisa e de ensino. $\mathrm{Na}$ realidade, ambas as atribuiçôes se encontram relacionadas e devem enriquecer e oferecer seu fruto à sociedade em que está inserida.

A pesquisa está ou deveria estar em todas as universidades que aspiram a oferecer melhores condiçôes de vida à sociedade, pois ela abre novas possibilidades, novos horizontes, novas descobertas e novos caminhos, além de propiciar um ensino com qualidade. Através da pesquisa, a universidade se torna universidade, e seu trabalho é reconhecido nacional e internacionalmente. Para Demo (1990), a atividade principal da universidade é a pesquisa, e o professor tem a incumbência de incentivar o aluno para que ele seja um novo pesquisador, pois, sem investigação, o ensino se reduz à reprodução. No parecer de Mosquera, "na universidade, a produção do conhecimento pode ser entendida como a mais importantes tarefa e objetivo" (2006, p. 85).

O Brasil, fruto de uma confluência cultural, do descobrimento à década de 60, sempre esteve atrelado aos interesses políticos e econômicos dos dominadores (portugueses, ingleses, norte-americanos, etc) e pouco realizou no campo da investigação científica nesse longo período. $\mathrm{Na}$ área científica, era considerado um país sem expressão no cenário mundial.

A partir da Reforma Universitária, fruto dos acordos Usaid/MEC, foi dada ênfase à pesquisa no Brasil para servir ao mercado internacional. $\mathrm{O}$ apoio da Capes, $\mathrm{CNPq}$, Finep, órgãos governamentais e das Fundações de Apoio à Pesquisa, possibilitou, principalmente aos professores das universidades federais, financiamento aos projetos de pesquisa. Essas investigações, pelas características da época, eram, na grande maioria, 
quantitativas, seguindo o enfoque tradicional. É provável que o Brasil tenha sido o país que mais cresceu nesse período. Castro (1985), referindo-se ao assunto, diz que o que país tinha de ciência, mesmo após a Segunda Guerra Mundial, era inexpressivo. Nesse sentido, havia as sementes e algumas amostras, mas o crescimento na década de 70 foi espetacular. É bem provável que não haja outro país que tenha alcançado um avanço tão significativo. De 1973 a 1980, a participação do Brasil no ISI praticamente triplicou.

Cabe indagar: por que o Brasil, em pleno Regime Militar, introduziu a pesquisa como função básica da universidade quando esta foi praticamente banida em todas as universidades da América Latina durante as ditaduras? Quais os verdadeiros interesses que estavam subjacentes?

$\mathrm{Na}$ década de 80, com a reabertura política, o resgate da cultura popular, o interesse pelos problemas sociais, econômicos e culturais da sociedade brasileira, os enfoques alternativos (Dialética de Marx, Hegel, a Fenomenologia, Pesquisa-ação, a Pesquisa Participativa) surgem como reação ao enfoque tradicional, numa tentativa de contextualizar a educação. Conforme Warde (1992), o exame de um número significativo de trabalhos produzidos nas décadas de 70 e 80 mostra a permanência de algumas características marcantes na literatura educacional que foram constatadas em outras épocas na produção científica, e o aparecimento de alguns traços novos. De meados da década de 80 até os dias atuais, emergiram a produção teórica e as pesquisas relativas aos movimentos sociais, as investigações históricas e historiográficas e os trabalhos sobre o cotidiano escolar e questóes da produção de conhecimentos no âmbito da escola como tendências, possivelmente atualizadas, sob um novo linguajar. Essas tendências não se dirigem ao Estado como destinatário e objeto preferencial.

Para Luna (1992), com a mudança dos paradigmas de pesquisa e principalmente com a introdução das denominadas metodologias alternativas, os problemas de pesquisa foram sendo alterados, e isso significou, na maioria dos casos, uma mudança substantiva na natureza daquilo que, até então, se denominava de variáveis. $\mathrm{O}$ aumento na complexidade dos fenômenos em estudo, a ênfase nos processos, a insistência na recuperação do desenvolvimento histórico configuram desenhos de pesquisa para os quais testes estatísticos tradicionais para determinação de fidedignidade e generalidades têm pouca utilidade (o que não significa que não sirvam a outros propósitos).

Apesar do avanço expressivo da pesquisa, em nossas universidades continua a carência desse tipo atividade em ciências naturais, humanas, nas letras e artes e, principalmente, projetos de ensino com pesquisa. De um lado, percebe-se o espetacular crescimento que a pesquisa teve nas três últimas décadas no Brasil. Esse crescimento, apesar de exclusivamente quantitativo, pode ser comparado com o dos países do primeiro mundo e coloca o Brasil em destaque no cenário mundial. De outro lado, uma reflexão sobre a contribuição desse vertiginoso número de pesquisas à melhoria de vida da população brasileira é procedente. É necessário analisar essa questão qualitativamente e levar alguns questionamentos, tais como: 
- qual a contribuição das pesquisas realizadas para a melhoria da qualidade de vida da população brasileira, principalmente a marginalizada?

- qual a contribuição das pesquisas realizadas para amenizar a miséria e a fome?

- qual a contribuição dessas pesquisas realizadas para a melhoria da qualidade da educação?

- essas pesquisas contribuíram para uma distribuição eq"uitativa da renda nacional, assegurando igualdade de oportunidades a todos?

- qual a percentagem dessas pesquisas que contribuíram significativamente para a sociedade?

Sabe-se que boa parcela de investigações científicas são realizadas unicamente para atender às exigências acadêmicas dos programas de pós-graduação espalhados nas universidades brasileiras. Nesse caso, a pesquisa é efetuada como requisito parcial à obtenção de um título, e seus resultados, na grande maioria, são depositados em bibliotecas e ultimamente on line. Geralmente, estudantes que necessitam realizar uma pesquisa são seus únicos leitores. Outra parcela significativa desses trabalhos são efetuadas por docentes pesquisadores para justificar a dedicação exclusiva e/ou aplicação de verbas públicas. É mister reconhecer que, em parcela proporcionalmente menor, há pesquisas de alto nível realizadas nas universidades brasileiras. Estas, além de favorecer o desenvolvimento do país, abrem novas perspectivas em áreas como medicina, engenharia, tecnologia, informática e humanidades. Lamentavelmente esses avanços atingem pequena parcela da população e são inexpressivos perante a quantidade de estudos inúteis realizados ao longo de décadas.

Conforme já foi exposto, a pesquisa é a função principal da universidade, e ela tem, entre outras, a premissa de ajudar a melhorar o ensino, principalmente através do ensino com pesquisa. Cabe à universidade produzir o saber e não, conforme vem fazendo ao longo dos séculos, simplesmente repassar e/ou reproduzir os conhecimentos advindos de outras áreas. Belloni diz:

A função da universidade é apenas uma: gerar saber. Um saber comprometido com a verdade porque ela é a base da construção do conhecimento. Um saber comprometido com a justiça porque ela é a base das relaçôes humanas. Um saber comprometido com a beleza porque ela possibilita a expressão da emoção e do prazer, sem o que a racionalidade reduz o humano a apenas uma das possibilidades. Um saber comprometido com a igualdade porque ela é a base da estrutura social inerente à condição humana. Um saber comprometido com o verdadeiro, o justo, o igualitário e o belo; é, em verdade, um compromisso com a transformação da sociedade, pois estes não são valores predominantemente estabelecidos e praticados na organização da vida humana, apesar de lhe serem próprios e inerentes (1992, p. 73).

Para a referida autora, esse compromisso com a verdade, com a beleza, com a igualdade e a justiça se realiza em um contexto de dicotomias, de pressōes e de contradições. É função da universidade gerar um saber que atenda aos problemas como um 
todo, sem restrição temporal ou espacial. Por outro lado, ela tem o compromisso de solucionar as questóes imediatas e locais. Ao mesmo tempo que a universidade tem a função de gerar saber comprometido com a ruptura e a inovação, com a busca do desconhecido, do inédito, da transformação da sociedade, é competência dela a preservação do patrimônio de cada povo. Portanto, ".... universidade vive a dicotomia do novo com o antigo, da inovação com a preservação, da construção com a superação" (BELLONI, 1992, p. 74).

\section{O ENSINO COM PESQUISA: UMA ALTERNATIVA METODOLÓGICA}

A proposta de ensino com e para a pesquisa é uma reação ao ensino conservador, que durante muitos anos foi utilizado como praticamente a única possibilidade de ensinar, pelos professores seguidores do modelo napoleônico. Este modelo, largamente utilizado nas universidades européias e países latino-americanos, intencionava a formação de profissionais dos quais necessitava o estado, sem necessariamente considerar o contexto econômico, social e cultural. Objetiva a manutenção do status quo e teve êxito na consolidação das estruturas do estado liberal. Por sua vez o modelo alemão humboldtiano, herdado do idealismo alemão do século XVIII, que teve como meta central o conhecimento científico, não necessariamente relacionado ao mercado de trabalho e ou às demandas da sociedade, objetivava formar pessoas com amplos conhecimentos, pois acreditava que uma sociedade com cidadãos formadas cientificamente seria capaz de avançar econômica, social e culturalmente. Ballester Brage (2001) assinala que a ciência surge na universidade para dar respostas ao homem às múltiplas perguntas e provas que a natureza propõe. A ciência é conhecimento e possui quatro vertentes essenciais: analisar a realidade; explicar os acontecimentos; prevenir acontecimentos e controlar os fatores intervenientes que atuam sobre ela.

No Brasil, a Lei 5.540/68, resultado dos acordos Usaid com o governo, seguindo o modelo de Humbold, estabeleceu o ensino, a pesquisa e a extensão como funções básicas da universidade. Cabe frisar que, apesar de ter sido introduzida a função da pesquisa com a Reforma Universitária, em pouco mudou a metodologia de ensino adotada pela maioria dos professores das instituições de ensino superior e, hoje, mesmo em pleno século XXI, com raras exceções, a educação bancária (Freire) ainda é priorizada. Mesmo que a pesquisa já esteja consolidada em muitas universidades, através de programas sctrito sensu, projetos de pesquisa e da própria iniciação científica, o ensino com pesquisa, como metodologia de trabalho, está longe de ser uma realidade para a grande maioria dos docentes do ensino superior. Certamente poucos são conhecedores desta proposta inovadora, de seus benefícios para a melhoria da qualidade do ensino e das instituições de ensino superior, e poucos docentes buscam inovar ou introduzir novas metodologias e tecnologias. 
O termo inovação no ensino goza de um clima favorável, tanto no que se refere ao professorado como à sociedade em geral. Para Perez Serrano (1990), a inovação pode ser fruto da investigação e manifestar-se através da modificação de métodos, técnicas, procedimentos, estruturas e mudanças de comportamento em determinados grupos, porém também pode ser levada a cabo por outras vias. Para realizar qualquer experiência que tenha impacto inovador, é preciso despertar a capacidade de invenção, de estímulos, de iniciativas, assim como a criação de uma atmosfera favorável em que tanto os professores como os alunos se sentem estimulados para indagar, descobrir, refletir e fomentar mudanças, pois o ensino deve ser questionador, aberto, despertar a curiosidade e a motivação para a inovação, para a criatividade, para o descobrimento audaz de novos âmbitos de conhecimento ou de habilidades. Portanto, a autora propóe um ensino criativo, que motive a curiosidade e a interrogação, que evite o dogmatismo, as certezas absolutas e a excessiva estabilidade e se caracterize por despertar a inquietude e a constante busca.

A inovação escolar busca, em essência, aportar algo novo, que objetiva melhorar a prática educativa. Inovar é reelaborar, reconstituir, reescrever. É acrescentar. É deixar de lado o modismo, a acomodação, para construir e gerar mudanças significativas no ensino, para que a aprendizagem se torne mais significativa, dinâmica, prazerosa e menos cansativa, estafante e obrigatória."A inovação, antes de manter o sistema, deve ir ao encontro das necessidades, desejos e expectativas dos educandos, pois são estes os sujeitos que constroem e reconstroem a história" (LAMPERT, 2000, p. 34).

Portanto, a inovação se aprende, e o docente, para aprender a inovar deve ter autonomia, criatividade, independência, espírito jovem, abertura para novas idéias e principalmente predisposição para inovar. Além destas características, é indispensável que o professor disponha de conhecimentos, habilidades, atitudes de melhora profissional e de espaço apropriado para introduzir, paulatinamente, inovações em sua práxis de ensino.

Parte-se da tese de que a universidade inovadora e empreendedora deverá oferecer uma pedagogia diferenciada que atenda às novas exigências de uma sociedade cambiante. A universidade precisa repensar suas convicções. Através de uma visão de criticidade, deverá estudar novos modos de pensar, ler o mundo, gerar conhecimentos e conduzir o processo ensino-aprendizagem. Nesta direção, Dupont e Ossandon (1998) assinalam que a universidade parece ocultar a complexidade do sujeito que aprende, a complexidade da sociedade que evolui ao ritmo de paradigmas múltiplos e complementares. "Por falta de uma verdadeira modificação das práticas pedagógicas e de uma tentativa de aproximação sistêmica dos problemas, a universidade corre o risco de se cristalizar e... de cristalizar" (p. 22). A práxis de produção do conhecimento deverá estar aberta a novas alternativas, até então refutadas, para justificar e explicar fenômenos, mesmo de forma temporária. "Os desafios culturais, teóricos, metodológicos e éticos colocados pela pós- 
modernidade esperam da universidade uma resposta corajosa e urgente" (SANTOS FILHO, 1998, p. 66).

A pesquisa é um dos requisitos metodológicos indispensáveis para qualquer profissional em uma sociedade global, competitiva, complexa, pragmática, utilitarista, imediatista, pluralista, subjetiva, onde há uma saturação de informações fragmentadas, uma decadência do Estado e um descrédito em relação à educação. Bagno diz que ...”a pesquisa é uma atividade que, embora não pareça, está presente em diversos momentos do cotidiano, além de ser requisito fundamental num sem número de profissōes" (2004, p. 16). A pesquisa é o fundamento de toda e qualquer ciência digna, séria e comprometida com a verdade e a realidade. Daí a importância, conforme Elliott (1990), do professor e aluno estarem efetivamente envolvidos como participantes ativos no processo investigativo.

O ensino com pesquisa e para a pesquisa é uma das opções metodológicas que o professor poderá utilizar para redimensionar o processo de ensino sob uma ótica diferente, capaz de envolver professor e aluno como sujeitos do processo e não meramente objetos, pois o sistema educacional brasileiro foi e é, ao longo da história, competente para formar uma massa de profissionais apolíticos, consumidores, indivíduos desprovidos de uma preocupação social e coletiva e interessados em satisfazer os seus próprios interesses de consumo supérfluo. No parecer de Behrens (2005), a mudança paradigmática no advento da sociedade do conhecimento desafia as instituiçôes de ensino a repensarem a sua prática pedagógica. "A superação da reprodução do conhecimento, da visão newtoniano-cartesiana, leva os educadores a investigar como propiciar metodologias que atendam às exigências do paradigma emergente proposto pelos cientistas, enfaticamente, no final do século XX" (p. 80).

O ensino com pesquisa, etapa inicial e característica dos cursos de graduação e de pós-graduação, é uma poderosa ferramenta de que se pode lançar mão para introduzir o aluno na iniciação científica, despertando-lhe o gosto pela investigação. Para Poali (1988), o ensino com pesquisa trata das habilidades intelectuais básicas, da reflexão e, no caso de continuidade em termos de formação para a pesquisa, implica acrescentar outras qualidades, como originalidade e domínio de um campo de conhecimento. O ensino para a pesquisa, etapa posterior, atribui ênfase aos programas de pós-graduação, especialmente stricto sensu e tem o seu encargo a formação do pesquisador.

Cabe mencionar, a título de esclarecimento ao leitor, que a Iniciação Científica, mesmo que não tenha, na maioria das vezes, uma relação direta, com o ensino com pesquisa, problemática deste estudo, fomenta a pesquisa entre os graduados e é sem dúvida uma proposta brilhante do $\mathrm{CNPq}$, pois ela se constitui em uma das melhores formas de aprendizagem, onde o aluno é capaz de construir e reconstruir, através da teoria/prática, o conhecimento.

A iniciação científica é uma atividade do Conselho Nacional de Pesquisa (CNPq) e está voltada à formação do futuro cientista. Esta modalidade de bolsa foi introduzida na 
década de 50 e continua até hoje como uma das poucas possibilidades de incentivo à pesquisa na graduação. A iniciação científica deveria estar presente na política de pesquisa das instituições superiores, principalmente, das universidades. Através do $\mathrm{CNPq}$, estas bolsas podem ser concedidas no âmbito de projeto de pesquisa (repassadas diretamente ao coordenador do projeto, após avaliação por Comitê do CNPq) e no âmbito do Programa Institucional de Bolsas de Iniciação Científica - Pibic (as quotas de bolsas são repassadas às instituiçôes). O Pibic tem como objetivos principais: despertar vocação científica e incentivar talentos potenciais entre os discentes de graduação, através da participação em projetos de pesquisa, preparando-os para o futuro ingresso na pósgraduação; contribuir para diminuir o tempo médio de titulação do mestre e doutor; e contribuir para diminuir as disparidades regionais na distribuição da competência científica no País. A avaliação dos trabalhos é realizada, anualmente, por intermédio de seminários, nos quais são apresentados os resultados dos planos de trabalho de cada discente. Os trabalhos são publicados em livros de resumos ou anais.

Portanto, o Pibic é uma das atividades estratégicas do CNPq, com impactos imediatos no fortalecimento da política de iniciação científica e melhoria da qualidade de ensino da educação superior; a longo médio prazo poderá ajudar na formação de uma massa crítica, participativa, consciente, responsável. A longo prazo, auxiliará na formação de quadro de recursos humanos de alto nível para as universidades e para os setores estratégicos da sociedade brasileira.

Em relação a essa problemática, Demo (2002) diz que a Iniciação Científica foi uma invenção providencial. Pensada para o aluno da graduação, acaba sendo igualmente um fator de grande renovação no professorado. Por sua vez, as instituições, aprendem a aproximar-se cada vez mais do ambiente acadêmico autêntico em que deveriam estar imersas. O aluno aprende a pesquisar, aprende a habilidade mais básica para a sua permanente renovação profissional. Aprende a estudar melhorar; aprende de maneira reconstrutiva; reconstrói o conhecimento sistematicamente e este tipo de aluno terá um peso no futuro do país, pois é a principal fonte para a instituição de novas vocações docentes.O professor, por sua vez, precisa ser capaz de orientar um processo de pesquisa, que supõe que ele saiba pesquisar. $\mathrm{O}$ ambiente acadêmico será impulsionado pela reconstrução sistemática e permanente do conhecimento.

Afinal, o que significa ensino com pesquisa e quais as principais etapas de processo? Qual a importância da escolha deste procedimento de ensino? - Que respaldo teórico tem essa proposta de trabalho? Que mudanças substanciais trará no papel do professor e do aluno? - Quais são os desafios e perspectivas desta proposta metodológica no ensino superior brasileiro?

O ensino com pesquisa, neste estudo, será entendido como uma seqüência organizada de situações estimuladoras e desafiadoras de aprendizagem, na qual professor e alunos estão envolvidos como sujeitos do processo, na perspectiva de formação de 
cidadãos críticos, capazes de entender e transformar a realidade circundante. Aprender com pesquisa é um processo dialógico que envolve a problematização do conhecimento, a construção de argumentos e sua respectiva validaçãa. Em relação a este fenômeno, Moraes e outros assinalam que

A pesquisa em sala de aula pode ser compreendida como um movimento dialético, em espiral, que se inicia com o questionar dos estados do ser, fazer e conhecer dos participantes, construindo-se a partir disso novos argumentos que possibilitam atingir novos patamares desse ser, fazer e conhecer, estágios esses estão comunicados a todos os participantes do processo (2002, p. 11).

Latorre e Gonzáles (1992), em sua obra "O professor investigador: a investigação em sala de aula", apresentam um conjunto de reflexōes sobre as distintas etapas que configuram um projeto de pesquisa em sala de aula: como iniciar, como encontrar as informaçôes, como planejar as hipóteses, como registrar a informação, como interpretála, como e a quem comunicar e refletir sobre o próprio projeto. Para os autores, "investigar en el aula es un proceso mediante el cual los maestros pueden deliberar sobre su toma de decisiones y mejorar su práctica docente" (p. 8).

A partir do exposto, observe-se que o ensino com pesquisa abrange, no mínimo, três etapas, que estão inter-relacionados entre si e se complementam: questionamento, argumentação e comunicação.

O questionamento permanente dos alunos em relação aos conhecimentos, aos valores, à ética, à cultura, é essencial e é o primeiro e um dos passos básicos no processo de ensino com pesquisa. Ele ajudará o discente na formação/ reformação de conceitos, de princípios, de atitudes, de habilidades, de valores, de concepções de vida, etc. A existência da dúvida é a primeira premissa à construção da argumentação. Um questionamento bem encaminhado será condição para o êxito das etapas posteriores. Arnal, Rincón e Latorre (1994) afirmam:

Hacer preguntas es una actividad específicamente humana. A lo largo de la historia el hombre ha sido siempre un ser preocupado por entender y desentrañar el mundo que le rodea, por penetrar en sus relaciones y leyes, por orientarse hacia el futuro y descubrir el posible sentido de las cosas que existen a su alrededor, buscando a sus interrogantes. En la actualidad, sin embargo, el hombre utiliza diversas fuentes de conocimiento como la experiencia, los expertos o el razonamiento, ya sea deductivo, que permite pasar de lo general a lo particular, que partiendo de los datos particulares llega a generalizaciones (1994, p. 2).

Questionar não significa simplesmente perguntar sobre tudo, e a todo momento, de forma desordenada, mas desvendar um fenômeno de forma sistemática. Cabe ao professor organizar situaçóes de ensino em que o aluno possa entender o processo de questionar e fazê-lo, pois para Faundez (1985), todo o conhecimento começa pela pergunta, e o professor deverá ensinar aos alunos a perguntar. "É profundamente democrático começar a aprender a perguntar" (p. 45). Freire, por sua vez, assinala: 
$\mathrm{O}$ autoritarismo que cortou as nossas experiências educativas inibe, quando não reprime, a capacidade de perguntar. A natureza desafiadora de pergunta tende a ser considerada atmosfera autoritária, com a provocação à autoridade. E, mesmo quando isto não ocorre explicitamente, a experiência termina por sugerir que perguntar nem sempre é cômodo (1985, p. 46).

$\mathrm{Na}$ pós-modernidade é muito mais importante questionar do que dar respostas prontas, acabadas e absolutamente verdadeiras. Daí a importância da dúvida e da indagação. Para que o discente universitário saiba questionar, é indispensável que ele tenha conhecimento da realidade política, econômica, social e cultural do país, de sua realidade particular e certo domínio dos conteúdos básicos. Todo este processo de entendimento demanda tempo e envolvimento do professor e aluno como sujeitos do processo, pois segundo Elliott (1990), o ensino é um autêntico processo de investigação para a compreensão, a reconstrução individual e coletiva do conhecimento.

Portanto, o questionar exige um clima democrático, onde há liberdade de expressão e respeito às diferenças individuais. $\mathrm{O}$ questionar é uma habilidade latente do ser humano, mas deve ser aperfeiçoada no meio acadêmico. Um questionamento bem encaminhado, certamente, produzirá e organizará argumentos fundamentados e, certamente, garantirá êxito no desencadeamento do processo investigativo.

A argumentação é a operação discursiva do pensamento. Ela faz parte da vida das pessoas, pois a sociedade é comunicativa e argumentativa. Ramos afirma:

A argumentação é, pois, uma variedade discursiva com a qual se pretende defender uma opinião e a partir dela persuadir ou convencer um interlocutor mediante provas ou motivos que estão relacionados ao objeto da argumentação. Isso se dá através da lógica ou leis da razão humana, da dialética ou procedimentos que se poem em jogo para provar ou enfrentar algo e a retórica ou uso de recursos lingüísticos com o fim de persuadir, mobilizando âmbito não-racionais, como são os afetos, as emoções e as sugestões. A argumentação é essencialmente comunicação, diálogo, discussão, controvérsia (2002, p. 38).

Nesta etapa, o aluno, usando diferentes fontes de consulta, deverá buscar nos jornais, nas revistas, em livros, em relatórios, na Internet, através do diálogo, de entrevistas com pessoas especializadas ou, ainda, através de experimentos, informações para equacionar a problemática em questão. À luz destas informaçôes, deverá o discente organizar suas idéias; interpretar, analisar e avaliar as informações para emitir juízos e dar respostas confiáveis ao seu questionamento. É importante frisar que as inferências e conclusões são temporárias, pois, hoje em dia, com o avanço da ciência e da tecnologia, o conhecimento é dinâmico, inacabado e mutável. Esta etapa é extremamente importante porque o discente terá que buscar na teoria e ou na prática relaçóes e argumentos que justificam ou que possibilitam encaminhamentos plausíveis ao questionamento. É imprescindível que o professor esteja presente nesse momento para ajudar a selecionar bibliografias e na indicação de caminhos viáveis. Certamente será decisivo para que o discente não desista, consiga avançar e alcançar sucesso. $\mathrm{Na}$ etapa da argumentação, o discente tem a possibi- 
lidade de relacionar teoria/prática ou prática/teoria, elaborar argumentos fundamentados capazes de dar respostas a seu questionamento.

Portanto, a argumentação, diálogo de idéias entre sujeitos, é usada para convencer e persuadir sujeitos. Ela não se constitui na afirmação da verdade, pois um verdadeiro diálogo jamais esgota a possibilidade de investigar a verdade. $\mathrm{O}$ aluno, para saber argumentar, necessita compreender as opiniōes alheias, entender os argumentos (aceitando-os ou recusando-os) e até contra-argumentar.

A comunicação constitui-se na culminância do processo de ensino com pesquisa. Nesta etapa, o discente, através de diferentes procedimentos (seminário, painel, exposição dialogada, produção de artigo, elaboração de relatório, comunicação em congresso, a própria sala de aula, etc) terá a possibilidade de comunicar os resultados de seu trabalho. É indispensável cautela e criticidade neste momento. $\mathrm{O}$ aluno aprenderá, quer através da escrita quer de maneira oral, a se comunicar de forma clara, seqüencial, objetiva e fundamentada, o que auxiliará na formação de sua personalidade. É fundamental que o discente, mesmo que faça a comunicação dos resultados de forma verbal, apresente o relatório por escrito, pois na atualidade, com exceçôes, os universitários apresentam enormes dificuldades em redigir textos. Dessa forma, estará exercitando e aprofundando a habilidade de escrever, imprescindível na sociedade hodierna.

O ensino com pesquisa é um procedimento metodológico que poderá ser adotado pelos professores da educação superior e ajudará de forma significativa na melhoria da qualidade de ensino. Mesmo que esta modalidade de ensino tenha surgido na década de 60 no Reino Unido, para muitos dos docentes brasileiros constitui-se em uma inovação no processo educacional. Para Bernal Guerrero, "la investigación en el aula es, sin duda, una clave del desarrollo científico de la enseñanza" (1989, p. 38). Segundo Nisbet (1982), ela desperta a agudeza e a reflexão, resolve problemas, estimula o debate, o intercâmbio de opinióes, aprofunda o entendimento e promove a flexibilidade e a adaptação. Behrens assinala que "a metodologia do ensino com pesquisa assenta-se na busca do conhecimento pelos alunos e pelos professores, com autonomia, com criticidade e com criatividade. A indissociabilidade do ensino e da pesquisa gera um redimensionamento na prática pedagógica" (2005, p. 84). Nesta direção, Freire argumenta que

...toda a docência implica pesquisa e toda pesquisa verdadeira implica docência. Não há docência verdadeira em cujo processo não se encontre a pesquisa como pergunta, como indagação, curiosidade, criatividade, assim como não há pesquisa cujo andamento necessariamente não se aprenda porque se conhece e não se ensine porque se conhece e não se ensine porque se aprende (1992, p. 192).

$\mathrm{Na}$ proposta de ensino com pesquisa é indispensável que a teoria esteja aliada à prática durante todo o processo, a pesquisa é a conexão entre teoria/prática e ou vice versa; uma renova e reconstrói a outra, e não se pode pensar em teoria acabada, final, imutável da mesma forma não há prática definitiva. 
Diferentes autores: Latorre e Gonzáles, (1992), Demo, (1994), Zan (1992), (Moraes, 2002), Lima (2004) e Behrens (2005) salientam a importância da escolha da pesquisa como metodologia de trabalho. Para Freire, "não há ensino sem pesquisa e pesquisa sem ensino. Esses que-fazeres se encontram um no corpo do outro. Enquanto ensino contínuo buscando, reprocurando. Ensino porque busco, porque indaguei, porque indago e me indago. Pesquiso para constatar, constatando, intervenho, intervindo educo e me educo. Pesquiso para conhecer o que ainda não conheço e comunicar ou anunciar a novidade" (1996, p. 32).

Lima pondera que tornar a sala de aula um ambiente de pesquisa é uma decisão associada com a perspectiva construtivista, pois o professor acredita ser o conhecimento uma construção do ser humano e não uma cópia da realidade. A autora salienta que esta escolha não supõe transplantar para a sala de aula a pesquisa em sua acepção clássica, mas prevê criar situações em que o educando lide, de forma sistemática, com alguns pressupostos inerentes ao ato de pesquisar, como: questionamento, argumentação, produção escrita, permanente diálogo entre situação do cotidiano e conteúdos escolares. O questionamento é vital à construção do conhecimento e pode significar um potente instrumento de qualificação formal e política do processo educativo. A argumentação visa qualificar o aluno para reunir elementos a fim de fundamentar uma determinada idéia ou demonstrar a compreensão de determinado conteúdo. A escrita representa a possibilidade de o educando aprender a posicionar-se como autor, produzindo o seu próprio material e aprender a reconstruir textos já existentes. A discussão de textos produzidos constitui-se em fórum de discussão. Abordar os conteúdos relacionando-os a diferentes vivências do cotidiano é um dos princípios da educação pela pesquisa e é essencial à compreensão da realidade. Concluindo, a autora diz que

a pesquisa em sala de aula é uma das opçôes capaz de dar conta de orientar os educandos em seus planos de vida e, ao mesmo tempo, consolidar valores de cidadania, qualificando, deste modo, o sujeito para viver na sociedade contemporânea. Eleger a pesquisa como princípio didático é, antes de tudo, comprometer-se com as premissas acima, sendo esta decisão, ao mesmo tempo, decorrência de uma série de escolhas que o professor realiza ao organizar a prática docente, calcando em suas crenças sobre o modo como os alunos aprendem. Ao escolher a educação pela pesquisa, o professor cria espaços efetivos para que o aluno questionar, argumentar e escrever, entrelaçando conteúdos escolares e realidade, num processo que visa à realização de aprendizagem com qualidade formal e política (p. 168).

O ensino com pesquisa não visa a formar um profissional pesquisador, mas incentivar o discente a entender o processo investigativo, ser capaz de usá-lo e conhecer a realidade de forma contextualizada. Por sua vez, para o professor a pesquisa é vista como fonte inesgotável de produção de novos conhecimentos e transformações. Além disso, esta possibilidade metodológica pode tornar o professor um pesquisador, isto é, capaz de questionar e refletir sobre a sua prática, que sem dúvida trará grandes benefícios ao 
profissional, ao processo de ensino e à universidade. Todo este processo demanda mudanças paradigmáticas e metodológicas na condução do processo de ensino-aprendizagem. Para articular ensino à pesquisa, necessitamos nos reeducar; entender que os fenômenos do processo de ensinar-aprender são complexos e possuem maior dificuldade epistemológica; que o ensino tem caráter pluraparadigmático e plurimetodológico e aceitar que o ato de pesquisa inicia-se na sala de aula de qualquer nível de ensino. Seguindo esta linha de pensamento, Cunha afirma que "....é preciso recomeçar, experimentar, ousar, sistematizar, discutir, registrar. Só assim, aos poucos, construiremos um novo conhecimento sobre o ensinar e o aprender de uma forma mais criativa, livre e produtiva" (1992, p. 18-19).

Assunção (1998), face às mudanças legais na formação de professores, conforme determina a Lei 9.394/96, percebe a necessidade de se romper com a lógica tradicional de currículo preconizando a formação de professor sustentada no processo de investigação, que deve estar presente na formação de docentes formadores e de aluno, futuro profissional. Neste sentido, o ensino articulado à pesquisa torna-se ponto fulcral. Com a pesquisa no ensino, romper-se-á com a falta de articulação na formação do professor com a realidade, deixando-o mais seguro e capaz alterar as situaçôes do cotidiano.Com o ensino vinculado à pesquisa será possível se vislumbrar a possibilidade de se compreender a sala de aula e o espaço escolar em geral, como um local permeado pelas mais diversas dimensões culturais, bem como pelas representaçōes e imaginários sociais. Portanto, será “.... um espaço em que as construções simbólicas, valores e crenças se fazem presentes e orientam as relações entre os sujeitos e, por isso, a necessidade de serem investigadas e compreendidas pelos professores" (p. 21). A autora propõe, inicialmente, as atividades de estágio, presentes na formação de professores, como uma possibilidade de experiência de ensino e pesquisa, na busca de uma articulação com os diferentes saberes presentes na formação do futuro professor.

Na proposta de ensino com pesquisa, o professor passará de um repassador de informaçōes para um mediador, desafiador, orientador e construtor e/reconstrutor de conhecimentos, numa atitude de permanente pesquisador. Esta possibilidade envolve o professor e o aluno como sujeitos ativos, autônomos, em um processo de contínuo e constante de questionar discursos, conceitos, princípios, realidades, através da construção de argumentos que possam reconstruir as verdades até então aceitas como universais. Como resultados imediatos, o aluno adquirirá a atitude de questionar, construir argumentos e comunicar resultados. Aprenderá a vivenciar os principais passos de pesquisa; coletar, interpretar e inferir sobre dados; produzir textos. Além disso, a referida proposta metodológica, favorecerá o desenvolvimento da autonomia do aluno; a trabalhar, de forma individual e grupal; a trabalhar de forma cooperativa e com outros; a conhecerse melhor; a superar limitaçōes; a dialogar com seus colegas e professores; a discutir e argumentar, defender idéias; aprender a aprender; a refletir sobre sua aprendizagem; a navegar no desconhecido; a aprofundar conhecimentos; a ter a capacidade de enfrentar desafios; e a construir, de forma contextualizada, um saber. 
Para alcançar esses altos imperativos, é indispensável que seja atribuída à investigação a devida importância. A pesquisa, desde o curso de graduação, deve ser abordada sistematicamente e com caráter teórico-prático. É essencial que o aluno se engaje na pesquisa, quer por meio de estágios com docentes e/ou institutos, quer praticando-a em sala de aula. É necessário reconhecer que a pesquisa se constitui num processo de aprendizagem. Aprende-se pesquisa, fazendo-a: "quanto antes a formação for iniciada, maior a probabilidade de seu sucesso" (AZZI, 1994, p. 77). Quanto à investigação na pós-graduação, Saviani (1991) diz que nos programas lato sensu, a pesquisa assume o papel de mediação para que o ensino, elemento definidor, seja alcançado. Em contrapartida, nos programas stricto sensu, o ensino garante os requisitos para que a pesquisa, elemento definidor, seja atingido.

\section{DESAFIOS E PERSPECTIVAS:ALGUMAS QUESTÕES PARA REFLEXÃO}

O Sistema Brasileiro de Educação enfrenta problemas de toda ordem. Alguns são crônicos e vêm se arrastando ao longo dos últimos anos. A educação superior, inserida neste contexto, a partir da Reforma Universitária de 68, e da promulgação da Lei 9.394/96, está se expandindo quantitativamente em termos de instituiçôes de ensino superior e modalidades de ensino, sem, contudo, priorizar a qualidade do ensino. A partir desta legislação, percebe-se, grosso modo:

- Uma expansão das instituições privadas isoladas. Estes estabelecimentos de ensino, geralmente, contam com um pequeno número de alunos, poucas ofertas de cursos e priorizam o ensino. A pesquisa não se constitui em função básica. Os docentes, na maioria das vezes, são contratados em regime de tempo parcial e horistas, o que dificulta a realização de um trabalho de qualidade e voltado ao ensino com pesquisa.

- As universidades particulares com ou sem fins lucrativos, na sua grande maioria, enfrentam sérios problemas financeiros. Para competir e manter-se em funcionamento, por um lado, investem muito em infra-estrutura, tecnologia, informática e cursos novos de graduação e de pós-graduação. Por outro ângulo, esquecem em investir no professor, que é o principal recurso que a universidade possui. Além da falta de investimento em recursos humanos, as condições de trabalho, a falta de estabilidade no emprego, a reduzida carga horária, a sobrecarga de trabalho, a pouca autonomia que o docente possui para organizar o ensino (o importante é que o professor e o aluno estejam pontualmente na sala de aula e cumpram o horário e conteúdo determinado), pouco favorecem o desencadeamento de um ensino diferenciado e com pesquisa.

- Nas universidades federais, por um prisma, os professores, de maneira geral, são mais titulados, possuem carga horária de aula reduzida e, praticamente, o docente tem total autonomia de organizar as situações de ensino. As condições são favoráveis para 
que o docente inove, aborde o ensino com pesquisa e realize um ensino de qualidade. Por outro lado, geralmente, os docentes mais titulados priorizam a pós-graduação stricto sensu; as condições físicas de trabalho não são favoráveis, e os salários aquém do mercado. Além destes inconvenientes, nos últimos anos, há um contingente enorme de professores contratados temporariamente. Estes profissionais, alguns mais preparados que outros, atendem, na maioria dos casos, uma infinidade de disciplinas. Geralmente com sobrecarga de trabalho, dedicam-se exclusivamente a atender ao ensino.

Face ao exposto, parece que a realidade, de maneira geral, é pouco favorável a inovações e à melhoria da qualidade do ensino na educação superior. $\mathrm{O}$ que se percebe são iniciativas particulares e/ ou de grupo de professores lutando por espaços, melhores condições de trabalho e por maior autonomia. Estes, em muitos casos, conseguem levar a cabo algumas inovaçôes e melhorar a qualidade do ensino. Constituem-se em situações pontuais e particularizadas, porém louváveis e que merecem todo o apoio, porém, grosso modo, têm pouca representatividade em nível nacional. Por outro lado, é indispensável considerar que no contexto atual, há "aparentemente" disponibilidade de profissionais altamente qualificados (doutores). Estes profissionais, com o imperativo de permanecer no setor produtivo, necessitarão abrir seu próprio espaço e isso, necessariamente, passará pelo crivo do "diferencial". Certamente, com o passar dos anos, com a expansão do ensino virtual, somente o docente que for "diferencial", terá seu espaço assegurado na educação superior. Daí a importância de se trabalhar com a modalidade de ensino com pesquisa para ser um diferencial na melhoria da qualidade do ensino superior.

Quanto ao Sistema Brasileiro de Educação Superior, parece que os dados estatísticos (número de instituições autorizadas, credenciadas e recredenciadas, número de alunos matriculados e concluintes na graduação e pós-graduação, número de professores titulados etc.) são priorizadas em relação à qualidade da institucional e do ensino. $\mathrm{O}$ importante, nesta perspectiva, são os dados estatísticos altamente favoráveis, que mostram um suposto desenvolvimento e a formação do maior número de pessoas, pois o mercado de trabalho se incumbirá de selecionar os mais competentes. Os não-selecionados buscarão realizar cursos para se atualizarem ou se contentarão em assumir outras funções, muitas vezes, não tão qualificadas ou mesmo sem qualificação. O que vale é a lei da oferta e da procura num mundo globalizado e capitalista.

Em relação ao ensino com pesquisa, cabe frisar que o professor que escolhe este caminho tem a concepção de que a ciência não é pronta e acabada. É conhecedor de que o conhecimento é dinâmico e é produto da construção social. Aceita que o conhecimento é “...uma realidade-revelação-dialética, através da qual podemos desenvolver o curso do pensamento, ativar a inteligência, despertar a criatividade, pondo em funcionamento as atividades psíquicas superiores e tentando o difícil (mas fascinante) processo de solução de problemas e antecipação de inovações" (MOSQUERA, 2006, p. 85). 
A metodologia do ensino com pesquisa pode criar um ambiente inovador e participativo à construção de conhecimentos, através da utilização de diferentes fontes. Será uma possibilidade de propiciar um ensino de qualidade, procurando formar cidadãos do mundo, capazes de atuar com segurança, em parceria e em regime de cooperação, numa sociedade na qual as contradições e inseguranças são acentuadas e presentes no cotidiano. Por outro lado, é necessário que o docente e os discentes estejam preparados e tenham maturidade para encarar esta modalidade de trabalho, que tem início, bem definido, mas um desenvolvimento e fim não necessariamente previsíveis. Moraes enfatiza muito bem este aspecto, ao afirmar:

A pesquisa em sala de aula constitui-se numa viagem sem mapa; é um navegar por mares nunca antes navegados; neste contexto o professor precisa saber assumir novos papéis; de algum modo é apenas um dos participantes da viagem que não tem inteiramente definidos nem o percurso nem o ponto de chegada; o caminho e o mapa precisam ser construídos durante a caminhada (2002, p. 141).

Portanto, à luz da citação de Moraes, pode-se inferir que a pesquisa em sala de aula constitui-se em uma proposta metodológica de ensino na qual a flexibilidade e até a "improvisação" fazem parte. Todo o processo é construído passo a passo. O docente e os discentes, numa perspectiva sócio-histórica, são sujeitos engajados na construção ou reconstrução do conhecimento. Descobrem os caminhos, as ferramentas e as fontes viáveis ao longo do trajeto, conforme surgem os desafios e as perspectivas. É uma perspectiva dinâmica de aprendizagem, onde todo o desencadeamento precisa ser construído e em que o processo e o produto assumem o mesmo valor, diferente da concepção tradicional de ensino/aprendizagem, onde o processo está em detrimento do produto.

\section{Referências}

ARNAL, Justo; RINCÓN, Délio; LATORRE, Antonio. Investigación educativa: fundamentos y metodologías. Barcelona: Labor, 1994.

ASSUNÇÃO, Maria Madalena Silva de. A pesquisa na formação de professores (as) e no cotidiano escolar. Dois Pontos, Belo Horizonte, v. 4, n. 39, p. 20-24, nov./dez. 1998.

AZZI, Roberta Gurgel. Pesquisa (em psicologia e educação) e a universidade: alguns pontos para reflexão. Pro-posiçôes, Campinas, v. 5, n. 13, p. 77-85, mar. 1994.

BAGNO, Marcos Pesquisa na escola: o que é e como se faz.? 18. ed. São Paulo: Loyola, 2004.

BALLESTER BRAGE, Luís. Bases metodológicas de la investigación educativa. Palma: Universitat de les Illes Balears, 2001.

BEHRENS, Maria Aparecida. O paradigma emergente e a prática pedagógica. Petrópolis: Vozes, 2005.

BELLONI, Isaura. Função da universidade: notas para reflexão. In: BRANDÃO, Zaia et al. Universidade e educação. Campinas: Papirus: Cedes; São Paulo: Ande; Anped, 1992. p.71-78.

BERNAL GUERRERO, Antonio; VELÁZQUEZ CLAVIJO, Miguel. Técnicas de investigación educativa. Sevilla: Alfar, 1989. 
BOTEY, Juan. Universitat escoles d'adulta. Educar, Barcelona, n. 13, p. 81-94, 1988.

BRANDÃO, Zaia et al. Universidade e educação. Campinas: Papirus: Cedes; São Paulo: Ande: Anped, 1992.

BRASIL. MEC. INSTITUTO NACIONAL DE ESTUDOS E ESTATÍSTICAS ANÍSIO TEIXEIRA. Dados sobre o ensino superior. Brasília: Inep, 2006.

CASTRO, Cláudio de Moura. Há produção científica no Brasil? Ciência e Cultura, São Paulo, v. 37, n.7, p. 167-187, jul. 1985 .

CUNHA, Maria Isabel. O ensino com pesquisa. Cadernos de Educação, Pelotas, n. 1, p. 17-19, dez. 1992.

DEMO, Pedro. Pesquisa: princípio científico e educativo. São Paulo: Cortez: Autores Associados, 1990.

DEMO, Pedro. Iniciação científica - razões formativas. In: MORAES, Roque; LIMA, Valderez Marina do Rosário (Orgs.). Pesquisa em sala de aula: tendências para a educação em novos tempos. Porto Alegre: EDIPUCRS, 2002, p.103-126.

DEMO, Pedro. Pesquisa como metodologia de trabalho. Revista de Educação AEC, Brasília, v. 23, n. 90 , p. 13-19, jan./mar. 1994.

DUPONT, Pol; OSSANDON, Marcelo. A pedagogia universitária. Coimbra: Coimbra Editora, 1998.

ELLIOTT, John. La investigación-acción en educación. Madrid: Morata, 1990.

FREIRE, Paulo; FAUNDEZ, Antonio. Por uma pedagogia da pergunta. 2. ed. Rio de Janeiro: Paz e Terra, 1985.

FREIRE, Paulo. Pedagogia da esperança: um encontro com a pedagogia do oprimido. Rio de Janeiro: Paz e Terra, 1992.

FREIRE, Paulo. Pedagogia da autonomia: saberes necessários à prática educativa. 9. ed. São Paulo: Paz e Terra, 1996.

HOFFMANN, Ricardo. Alienação na Universidade: crise dos anos 80. Florianópolis: UFSC, 1985. LAMPERT, Ernani. Experiências inovadoras e a tecnologia educacional. Porto Alegre: Sulina, 2000. LATORRE, Antonio; GONZÁLEZ, Romona. El maestro investigador: la investigación en el aula. 2. ed. Barcelona: Grao, 1992.

LIMA, Valderez Marina do Rosário A escolha da pesquisa como princípio educativo, Ciências \& Letras, Porto Alegre, n. 36, p. 151-169, jul./dez. 2004.

LUNA, Sérgio de Vasconcelos. Prestar serviços e pesquisar: algumas distinções necessárias. In: BRANDÃO, Zaia et al. Universidade e educação. Campinas: Papirus: Cedes; São Paulo: Ande: Anped, 1992, p. 27-32.

MORAES, Roque et al. Pesquisa em sala de aula. In: MORAES, Roque; LIMA, Valderez Marina do Rosário (Orgs.). Pesquisa em sala de aula: tendências para a educação em novos tempos. Porto Alegre: EDIPUCRS, 2002, p. 9-23.

MORAES, Roque. Educar pela pesquisa: exercício de aprender a aprender. In: MORAES, Roque; LIMA, Valderez Marina do Rosário (Orgs.). Pesquisa em sala de aula: tendências para a educação em novos tempos. Porto Alegre: EDIPUCRS, 2002, p. 127-142. 
MORAES, Roque. Produção em sala de aula com pesquisa: superando limites e construindo possibilidades. In: MORAES, Roque; LIMA, Valderez Marina do Rosário. (Orgs.). Pesquisa em sala de aula: tendências para a educação em novos tempos. Porto Alegre: EDIPUCRS, 2002. p. 203-235.

MOSQUERA, Juan Jose Moriño. Princípios da universidade no século XXI: universidade e produção do conhecimento. In: AUDY, Jorge Luis Nicolas; MOROSINI, Marília Costa (Orgs.). Inovação e empreendedorismo na universidade. Porto Alegre: EDIPUCRS, 2006. p. 70-88.

NISBET, Juan. Investigación educativa: el momento actual. In: DOCKRELL, Walter; HAMILTON, David. Nuevas reflexiones sobre investigación educativa. Madrid: Narcea, 1982. p. 8-19.

PEREZ SERRANO, María Gloría. Investigación-acción: aplicaciones al campo social y educativo. Madrid: Dykinson, 1990.

POALI, Niuvenius. O princípio da indissociabilidade do ensino e da pesquisa: elementos para uma discussão. Cadernos Cedes, Campinas, n. 22. p. 27-52, 1988.

RAMOS, M. G. Educar pela pesquisa é educar para a argumentação. In: MORAES, Roque; LIMA, Valderez Marina do Rosário (Orgs.). Pesquisa em sala de aula: tendências para a educação em novos tempos. Porto Alegre: EDIPUCRS, 2002. p. 25-49.

SANTOS FILHO, José Camilo Universidade, modernidade e pós-modernidade. Educação Brasileira, Brasília, v. 20, n. 40, p. 41-72, jan./jul. 1998.

SAVIANI, Dermeval. Concepções da dissertação de mestrado centrada na idéia de monografia de base. Educação Brasileira, Brasília, v. 13, n. 27, p. 159-168, 1991.

SILVA, Rita de Cássia da; CASTRO CABRERO, Rodrigo. Iniciação científica: rumo à pós-graduação. Educação Brasileira, Brasília, v. 20, n. 40, p. 189-199, 1998.

TÓJAR HURTADO, Juan. Carlos. Innovación educativa y desarrollo profesional docente en la universidad. In: TÓJAR HURTADO, Juan Carlos; GUTIÉRREZ DE TENA, Roque. Manchado (Orgs.). Innovación educativa y formación del profesorado: proyectos sobre la mejora de la práctica docente en la universidad. Málaga: Universidad de Málaga, 1997.

WARDE, Mirian. Jorge. Pesquisa em educação: entre o Estado e a ciência. In: BRANDÃO, Zaia et al. Universidade e educação. Campinas: Papirus: Cedes; São Paulo: Ande: Anped, 1992.

ZAN, Andréia Cristina. Análise da prática pedagógica: a pesquisa em sala de aula, sua importância e seus tropeços - crônica extraída das vivências de um projeto. Educação \& Sociedade, São Paulo, n. 43, p. 489-494, dez. 1992. 


\section{Teaching with research: reality, challenges and perspectives in the Brazilian university}

\section{Abstract}

The subject dealt with in this article - teaching with research - is an innovative methodological proposition which has repercussions in the quality of teaching. First, the author will situate and set the context of the problem. During the discourse he will make it clear that research is the main function of the university and will analyze its importance. He will make a series of inquiries into this set of problems since questioning is one of the characteristics of contemporary researchers. Secondly, he will analyze research with teaching as one of the methodological possibilities that the higher education professor will be able to use. He will emphasize the meaning, the importance, the theoretical background, the changes that this methodology provokes in the role of professor and student. To culminate, he will make some considerations for reflection about the reality, the challenges and the perspectives of teaching with research in the Brazilian university.

Keywords: Teaching with research. Higher education. Teaching methodology. Research.

L’enseignement avec la recherche : réalité, défis et perspectives dans l'université brésilienne Résumé

L'enseignement avec la recherche, abordé dans cet article, est une proposition méthodologique innovatrice et qui a des répercussions sur la qualité de l'enseignement. Dans un premier moment, l'auteur situera et définira le contexte de la problématique. Pendant ce discours, il éclaircira que la recherche est la principale fonction de l'université et analysera son importance. Il posera une série de questions sur cette problématique, puisqu'une des caractéristiques des chercheurs modernes est justement le questionnement. Dans un deuxième temps, il analysera la recherche avec l'enseignement comme une des principales méthodologies que le professeur de l'enseignement supérieur peut utiliser. Il mettra en évidence le sens, l'importance, la base théorique, les changements que cette méthodologie provoque dans le rôle du professeur e de l'étudiant. Comme point culminant, il fera quelques pondérations pour la réflexion sur la réalité, les défis et les perspectives de l'enseignement avec recherche dans l'université brésilienne.

Mots clefs: Enseignement avec recherche. Enseignement supérieur. Méthodologie d'enseignement. Recherche.

\section{La enseñanza con investigación: realidad, desafíos y perspectivas en la universidad brasileña Resumen}

La enseñanza con investigación, abordada en este artículo, es una propuesta metodológica innovadora y que tiene repercusión en la calidad de la enseñanza. En una primera instancia, el autor ubicará y contextualizará la problemática. Durante el discurso, dejará claro que la investigación es la principal función de la universidad y analisará su importancia. Hará una serie de indagaciones acerca de esta problemática, pues una de las características de los investigadores contemporáneos es el cuestionamiento. En la segunda parte, analisará la investigación con enseñanza como una de las posibilidades metodológicas que el profesor de la educación superior podrá utilizar. Destacará el significado, la importancia, el respaldo teórico, los cambios que esta metodología provoca en el papel del profesor y del alumno. Por fin, tejerá algunas ponderaciones para reflexión acerca de la realidad, de los desafios y de las perspectivas de la enseñanza con investigación en la universidad brasileña.

Palabras-clave: Enseñanza con investigación. Educación superior. Metodología de la enseñanza. Investigación.

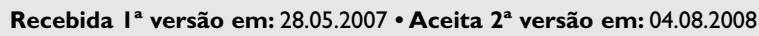

